

\section{DISCLAIMER}

This report was prepared as an account of work sponsored by an agency of the United States Government. Neither the United States Govemment nor any agency thereof, nor any of their employees, makes any warranty, express or implied, or assumes any legal liability or responsibility for the accuracy, completeness, or usefuiness of any information, apparatus, product or process disclosed, or represents that its use would not infringe privately owned rights. References herein to any specific commercial product, process, or service by trade name, trademark, manufacturer, or otherwise, does not necessarily constitute or imply its endorsement, recommendation, or favoring by the United States Government or any agency thereof. The views and opinions of authors expressed herein do not necessarily state or reflect those of the United States Government or any agency thereof. 


\section{DISCLAIMER}

Portions of this document may be illegible in electronic image products. Images are produced from the best available original document. 


\title{
PARTITIONING OF KRYPTON-85 IN LIQUID SCINTILLATION COCKTAIL
}

\author{
F. A. Hohorst
}

M. A. Sherlock

December 1994

Lockheed Idaho Technologies Company

PREPARED FOR THE DEPARTMENT OF ENERGY IDAHO OPERATIONS OFFICE UNDER CONTRACT DE-AC07-94ID13223 


\title{
PARTITIONING OF KRYPTON-85 IN IIQUID SCINTILIATION COCKTAIL
}

\author{
F. A. Hohorst and M. A. Sherlock
}

\section{Introduction}

Krypton is one of the noble gases. As such, it forms compounds only with exceptionally strong oxidizing agents. The concentration of krypton in air is 1.139 parts per million by volume. [1] In general, its behavior is best described as that of an ideal gas.

Krypton-85 is the longest lived of the common radioactive noble gases with a half life of 10.72 years. Gamma radiation at 513.990 $\mathrm{keV}$ has an intensity of only $0.434 \%$. Most decay is $B^{\circ}$ emission with a maximum energy of $687.0 \mathrm{keV}$ and an average energy of 251.4 $\mathrm{keV}$.[2] The analytical chemistry of krypton-85 is ariven by these factors. High concentrations may be gamma counted directly. Low levels are typically determined by more sensitive techniques such as liquid scintillation counting (LSC) where detection limits on the order of 1 picocurie (pCi) are routinely achieved. For a 5 standard cubic centimeter (scc) sample, this represents a concentration of $0.2 \mathrm{pCi} / \mathrm{scc}$, well below the DOE Air Immersion Derived Concentration Guideline (DCG) of $3 \mathrm{pci} / \mathrm{scc} .[3]$

As a gas, krypton in a sealed ISC vial distributes itself between the liquid phase and the gas phase. Some past work has used gamma counting at levels many orders of magnitude greater than those now achievable by ISC to study the distribution of krypton. $[4,5]$ This effect is of interest in the analytical chemistry of krypton-85 because geometrical considerations influence how much of the material in the gas phase decays generating particles which then impact the Iiquid phase where they may be counted. 
We report measurement of the distribution of krypton-85 between Iiquid and gas phase with one specific ISC cocktail, estimate the solubility parameters of krypton in that cocktail, estimate the rate at which equilibrium is attained, and apply this information to the determination of carbon-14 dioxide in the presence of krypton -85 .

\section{Experimental:}

All reagents used were analytical grade except where noted. The purity of prepurified cylinder nitrogen was $299.998 \%$. Certified mixtures of krypton-85 in nitrogen were purchased from Analytics, Inc. The specific activity was estimated at $30 \mathrm{Ci}{ }^{85} \mathrm{Kr}$ per Iiter of krypton. Fractionation of krypton isotopes was not considered significant in this work. These certified mixtures were diluted using typical pressure measurement techniques. Small aliquots in stainless steel cylinders were pressurized to approximately 7600 torr with nitrogen. No corrections for compressibility were made. optifluor (Packard Instrument Co.), a commercial alkylbenzene base liquid scintillation cocktail mixture $(\rho=0.90 \mathrm{~g} / \mathrm{cc}$, estimated average molecular weight 250), was used as received.

Iiquid scintillation vials were prepared in-house by reforming the threaded top of standard $20 \mathrm{~mL}$ low potassium glass vials to a $20 \mathrm{~mm}$ serum vial top. Washing and annealing at $560^{\circ} \mathrm{C}$ prepared the vials for use (or reuse). Grey butyl rubber stoppers (Alarich Chemical Co.) were then crimped in place with aluminum seals. The internal volume of these vials varied because they were individually fabricated but it was typically $21.7 \pm 0.5 \mathrm{~mL}$. The tips of common disposable hypodermic needles ( 0.89 by $25 \mathrm{~mm}$ ) were bent slightly to minimize coring. The LSC instruments used were a Packard Model $1900 \mathrm{CA}$ or a Beckman Model 5801 which had been calibrated with a wide range of standards. Efficiencies for both were approximately $45 \%$. Routine counting periods were 3 one-hour counts. 
Experiments were conducted at ambient temperature $\left(23 \pm 1^{\circ} \mathrm{C}\right)$. In typical experiments, a gaseous sample $(\approx 200$ torr corresponding to $\approx 5.3 \mathrm{scc}$ ) was placed in a vial of known volume. LSC cocktail (10 $\mathrm{mL}$ ) was "injected" from a glass syringe raising the pressure to approximately 380 torr $(0.50 \mathrm{~atm})$. (Actually, the reduced pressure drew the cocktail into the vial without assistance, thus assuring that no sample had been lost during these manipulations.) The vial was shaken to assure rapid attainment of equilibrium before counting.

In static tests of equibria conditions, vials which had been counted and which contained a calculated amount of krypton-85 were inverted and a $5 \mathrm{~mL}$ aliquot of cocktail carefully withdrawn. Fresh cocktail ( $5 \mathrm{mI}$ ) was immediately injected to return the liquid to its previous level. These vials were then shaken and recounted. simultaneously, the withdrawn aliquot was injected into a new vial containing approximately 200 torr of nitrogen followed by fresh cocktail ( $5 \mathrm{~mL})$. These new vials were shaken and counted. Vials containing 3500 to $4100 \mathrm{pci}$ had an uncertainty due solely to counting statistics of approximately \pm 9 pCi; vials containing 540 to $690 \mathrm{pCi}, \pm 4 \mathrm{pCi}$.

In dynamic tests of diffusion, sample aliquots (5 mL) were withdrawn as described above, injected into new vials containing 200 torr of nitrogen, fresh cocktail ( $5 \mathrm{~mL}$ ) added, but not shaken. These vials were handled gently with counting starting three minutes after preparation. The counting instrument was set for repetitive $10 \mathrm{~min}$ counts.

In studies of the separation of krypton from carbonate, a mixture was prepared using krypton/krypton-85 and carbonate/carbon-14. The cocktail used contained optifluor and $0.1 \mathrm{M}$ sodium hydroxide in a $2: 1$ ratio. In a brief test of this concept, three LSC vials were prepared. The first vial was a matrix blank. The second vial contained approximately $3.6 \mathrm{nCi}$ krypton-85 and $0.699 \mathrm{nCi}$ carbon-14. 
The third vial contained approximately $2.9 \mathrm{nCi}$ krypton-85 and 0.721 nCi carbon-14. The spectrum of the second and third vial showed two strong, distinct peaks attributable to these radioisotopes. Both pumping and purging were examined for their effectiveness in removing krypton as evidenced by the peaks present in the spectral display and the counting data. The second vial was subjected to three cycles of shake-evacuate-return to ambient pressure cycles. The third vial was subjected to a 30 minute purge of the headspace with 100 sccm nitrogen.

\section{Results}

The results of several determinations of the static equilibria conditions is presented in Table 1 . The calculations involved are relatively straight forward. If $\mathrm{X}$ is the mole fraction of krypton85 in the liquid phase, then

$$
\begin{aligned}
& x=2 * K I_{2} / K I_{1} / O R \\
& x=2 *\left(K I_{1}-K I_{2}\right) / K I_{1}
\end{aligned}
$$

where $\quad \mathrm{Kr}_{1}=$ krypton-85 in original vial

$$
\begin{aligned}
\mathrm{Kr}_{2} & =\text { krypton-85 remaining in original vial } \\
\mathrm{Kr}_{3} & =\text { krypton-85 removed in a } 5 \mathrm{mI} \text { aliquot } \\
\text { Recovery } & =100 *\left(K r_{2}+K r_{3}-K r_{1}\right) / K r_{1}
\end{aligned}
$$

The mean value of $x$ as determined using Equation 1 is $0.3261 \pm$ 0.0234 . This is in reasonable agreement with $\mathrm{X}$ as calculated from some data using Equation 2. However, there is an apparent correlation between the value of $\mathrm{x}$ as determined using Equation 2 
TABLE 1

Distribution of Krypton-85 in Vials

\begin{tabular}{|c|c|c|c|c|c|c|}
\hline Run & $\begin{array}{l}\text { Initial } \\
\text { Content } \\
\text { (pci) }\end{array}$ & $\begin{array}{l}\text { Content } \\
\text { After } \\
\text { (pci) }\end{array}$ & $\begin{array}{l}x \text { of } \\
\text { Orig } \\
\text { Vial } \\
\end{array}$ & $\begin{array}{l}\text { New } \\
\text { Vial } \\
\text { (pci) }\end{array}$ & $\begin{array}{l}x \text { of } \\
\text { New } \\
\text { Vial } \\
\end{array}$ & $\begin{array}{c}\text { Recovery } \\
(\%) \\
\end{array}$ \\
\hline 1 & 3573 & 3016 & 0.312 & 542 & 0.304 & -0.4 \\
\hline 2 & 3573 & 2821 & 0.421 & 573 & 0.321 & -5.0 \\
\hline 3 & 4104 & 3122 & 0.478 & 639 & 0.311 & -8.3 \\
\hline 4 & 4098 & 3051 & 0.511 & 632 & 0.308 & -10.1 \\
\hline 5 & 3830 & .3136 & 0.362 & 685 & 0.358 & -0.2 \\
\hline 6 & 3799 & 3219 & 0.305 & 613 & 0.322 & +0.8 \\
\hline 7 & 3812 & 3062 & 0.393 & 590 & 0.310 & -4.2 \\
\hline 8 & 3730 & 2929 & 0.430 & 686 & 0.368 & -3.1 \\
\hline 9 & 3595 & 2849 & 0.415 & 630 & 0.351 & -3.2 \\
\hline 10 & 3717 & 2929 & 0.424 & 623 & 0.335 & -4.4 \\
\hline \multirow[t]{3}{*}{11} & 3702 & 3026 & 0.365 & 554 & 0.299 & -3.3 \\
\hline & & & & $=$ & 0.3261 & \\
\hline & & & & $=$ & 0.0234 & \\
\hline
\end{tabular}


and the Recovery.

The solubility of krypton-85 in the cocktail can be expressed in terms of the Henry's constant and the ostwald coefficient. Assuming gas phase ideality, Henry's constant, $\mathrm{H}$, for a gas dissolved in the cocktail is defined as the ratio of the partial pressure of gas to the mole fraction of gas in the solvent, $\mathrm{H}=\mathrm{P}_{\mathrm{r}} / \mathrm{x}_{2} \cdot[6]$ The ostwald coefficient, $\mathrm{L}$, is defined as the ratio of volume of gas absorbed to the volume of the absorbing solvent, $L=V_{2} / V_{1} \cdot[5]$

The data presented in Table 2 was used to calculate Henry's Constant in atm/mole fraction and Ostwald's coefficient in $\mathrm{mL} / \mathrm{mL}$ at the vial temperature according to Equations 3 and 4 , respectively:

$$
\begin{aligned}
& H_{K x}=\frac{P_{K x} * 760 / P_{V i a I}}{X_{K x}} \\
& L_{K x}=\frac{\mathrm{X}_{K x} * \mathrm{~V}_{K x} *(273.2+\mathrm{t}) / 273.2}{10.0}
\end{aligned}
$$

where

$$
\begin{aligned}
P_{K r} & =\frac{\mathrm{V}_{K r} *\left(1-\mathrm{X}_{\mathrm{Kr}}\right) *(273.2+\mathrm{t}) / 273}{\mathrm{~V}_{\mathrm{vial}}-10.0} \\
X_{K x} & =\frac{\mathrm{V}_{\mathrm{Kr}} / 22414}{9.00 / 250}
\end{aligned}
$$

mole fraction krypton in liquid phase for a run

$$
\begin{aligned}
\mathrm{P}_{\text {vial }} & =\text { total pressure of gases in the vial, torr, } \\
V_{K r} & =p C i{ }^{85} \mathrm{Kr} * \frac{\mathrm{L} \mathrm{Kr}}{30 \mathrm{Ci}} * \frac{\mathrm{Ci}}{10^{12} \mathrm{pCi}} * \frac{10^{3} \mathrm{CC}}{\mathrm{L}}
\end{aligned}
$$


TABLE 2

Calculation of Henry's Constant and Ostwald's Coefficient

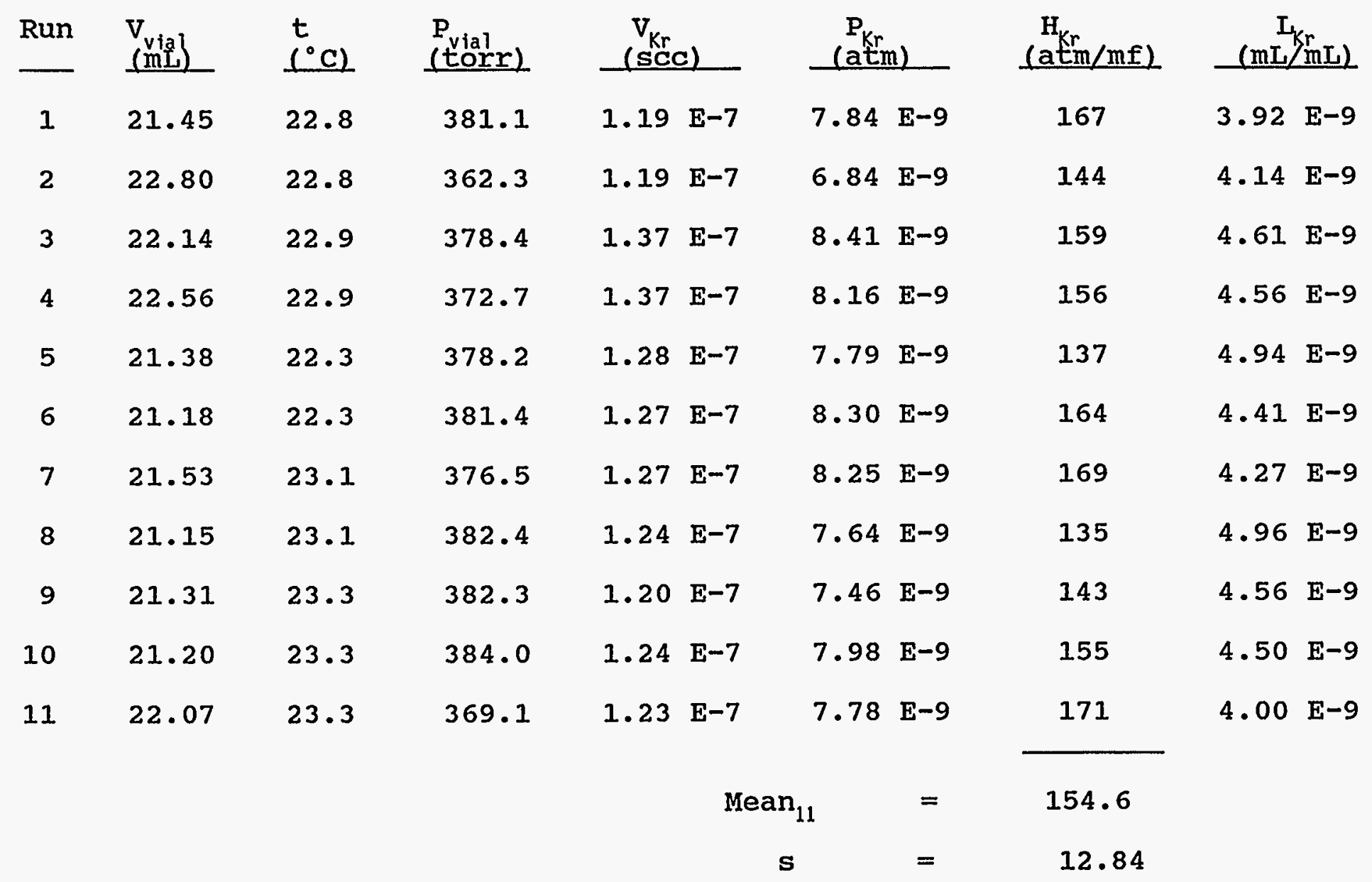




$$
\begin{aligned}
& t=\text { temperature of gas in vial, }{ }^{\circ} \mathrm{C}, \\
& \mathrm{v}_{\text {vial }}=\text { volume of vial, } \mathrm{cm}^{3},
\end{aligned}
$$

Diffusion of krypton-85 from the ISC cocktail to the headspace of the vial is illustrated in Figure 1 . The rate at which equilibrium is attained is a function of mixing. Curve la is a plot of successive 10 minute counts of the undisturbed vial. Curve $1 \mathrm{~b}$ is the activity of that vial after a vigerous $15 \mathrm{~s}$ shaking just prior to counting. Curve $2 \mathrm{a}$ and $2 \mathrm{~b}$ are $\mathrm{a}$ duplicate of the curve 1 . Curve 3 was shaken vigorously for $15 \mathrm{~s}$ after elapse of just an hour. The initial slightly higher points immediately after shaking are postulated to result from bubbles in the liquid phase which clear within $20 \mathrm{~min}$.

Carbon-14 has a half life of 5730 years. It is a pure $B^{-}$emitter with a maximum energy of $156.5 \mathrm{keV}$ and an average energy of 49.5 $\mathrm{keV}$.[2] Some resolution of the spectra of carbon-14 and krypton-85 is possible. However, the absorption of carbon dioxide by a strong base to form a nonvolation specie provides a more definative means of discrimination between these two radioisotopes. The krypton-85 in gas mixtures which contain both carbon-14 as carbon dioxide and krypton may be removed by either evacuations or purging the vial thus leaving the carbonate in the hydroxide solution in the vial. Thus the determination of carbon-14 by LSC should have improved specificity and accuracy. In these experiments, the third vial showed a very small residual peak in the krypton-85 region of the spectrum. After removal of krypton-85 under the described conditions, the second vial contained 0.704 nci calculated as carbon-14; the third vial, $0.791 \mathrm{nci}$.

\section{Conclusions}

The data in Table 1 permit calculation of $\mathrm{x}$ from the $5 \mathrm{~mL}$ aliquots of cocktail withdrawn from the equilibrated mixture using Equations 


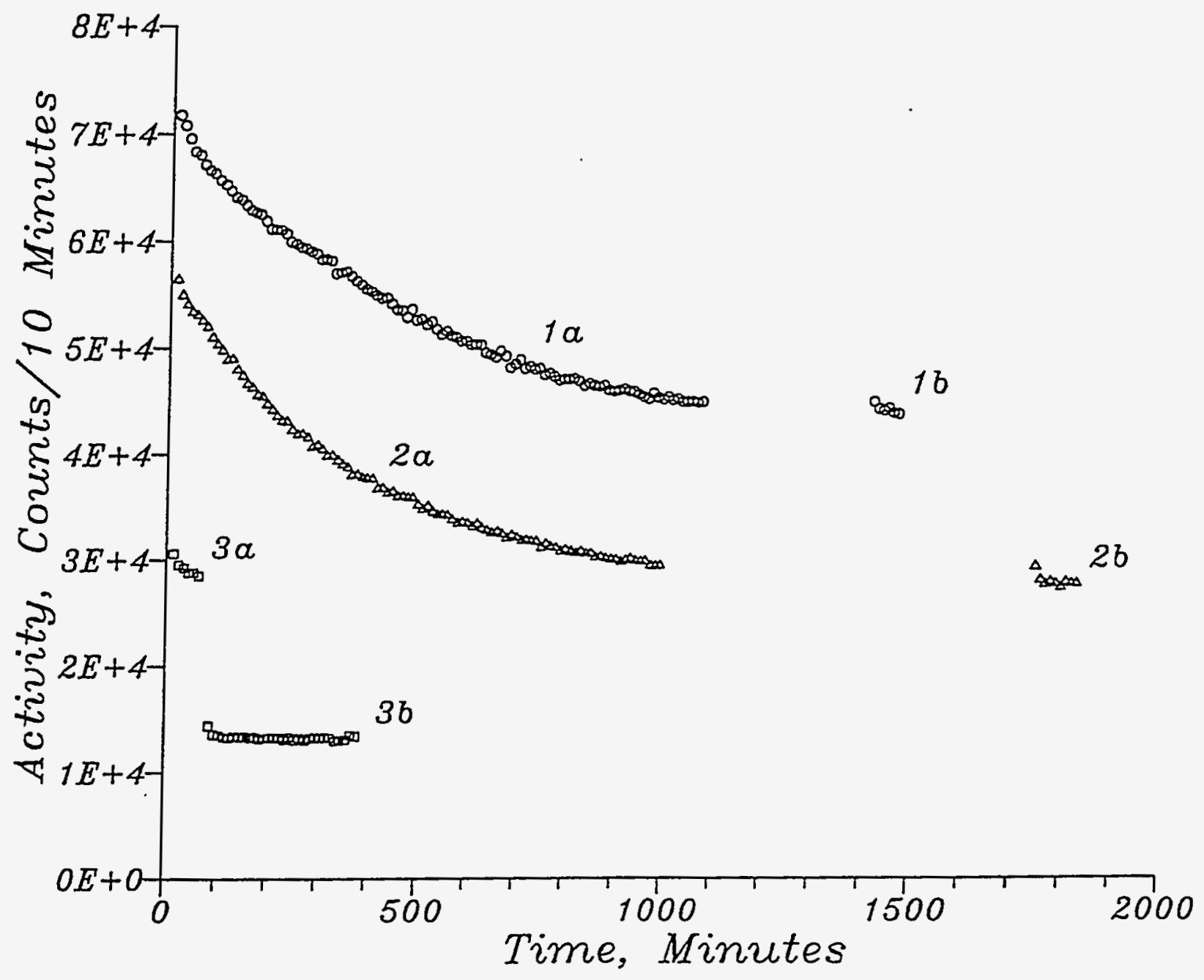

Figure 1. Apparent Activity of Vials as a Function of Time. - - Vial 1, $\Delta$ - Vial 2, 口 - Vial 3; a's are undisturbed successive recounts; b's are successive recounts after a vigorous shaking for 15 seconds. 
1 and 2. Based on these data, $(32.6 \pm 2.0)$ percent of the activity in a vial is in the Iiquid phase. Since the overall efficiency is 45.0\%, activity derived from krypton-85 in both the Iiquid phase and the gas phase is being detected.

The observed solubility parameters are reported in Table 2 . The mean experimental value of Henry's constant for krypton in optifluor under the conditions stated was $155 \pm 9 \mathrm{~atm} / \mathrm{mole}$ fraction at the $95 \% \mathrm{CL}$. The observed value is comparable to the value reported for the krypton-toluene system, $294 \mathrm{~atm} / \mathrm{mole}$ fraction, if one considers the difference in the molecular weight of the solvent.[5] Past work has utilized degassed cocktails. The present work used cocktail as received in order to evaluate experimental conditions of actual, routine samples.

The rate at which equilibrium is attained is a function of mixing. As shown in Figure 1 , Curves 1 and 2 , if left undisturbed in the vial, diffusion of krypton-85 to reach equilibrium is approached with a half life of $4.6 \pm 0.4$ hours under the conditions specified. Shaking a vial vigorously for $15 \mathrm{~s}$ causes rapid exchange as shown in curve 3. The initial slightly higher points in all three sets of data immediately after shaking are postulated to result from bubbles in the liquid phase which clear within $20 \mathrm{~min}$.

Carbon-14 may be determined in gas mixtures which contain both carbon-14 as carbon dioxide and krypton-85 in the manner described. With a mole fraction of 0.326 of krypton in the liquid phase, four shake-evacuate cycles effectively remove krypton, theoretically leaving $\leq 1.1 \%$ in the vial. Carbon-14 was subsequently determined by LSC using known techniques. The second vial contained $100.7 \%$ of the carbon-14 originally added. The third vial contained $109.7 \%$. The four shake-evacuate-return to ambient pressure cycles were thus somewhat more effective in removing krypton-85 than the headspace purge in these limited tests. 
Henry's constant was determined from the data as shown in Table 2. The volume of krypton present in the vials (Table 2, column 5) was typically $1.2 \mathrm{E}-7$ to $1.4 \mathrm{E}-7$ scc. Since the atmospheric concentration is $1.139 \mathrm{ppm}$, a $5.3 \mathrm{scc}$ sample of air contains approximately $6.0 \mathrm{E}-6 \mathrm{scc}$ of krypton. Thus these data show that the concentrations are somewhat comparable to and should be directly applicable to air samples and samples of similar composition.

The time constraints on this work narrowed its scope to specific conditions. The fundamental assumption was that the removal of an aliquot of cocktail is of short duration and preserves equilibrium conditions. In retrospect, the approach taken might be improved upon by I) examination of a wider variety of concentrations, cocktails, and conditions, and 2) increasing the vial pressure to atmospheric pressure after addition of cocktail. The latter action would overcome any tendency of the total vial pressure to increase during the course of the experiment due to septum leakage with subsequent potential impact on results.

\section{Acknowledgements}

We thank the Department of Energy for a Teacher Research Associate (TRAC) appointment for one of us (MAS) at the Idaho National Engineering Laboratory (INEL) during the summer of 1994.

\section{References}

1. A. H. Crockett and K. C. Smith, 5. The Monoatomic Gases: Physical Properties and Production, in Comprehensive Inorganic Chemistry, Volume 1 (A. F. Trotman-Dickenson, Exec. Ed.) (Execter: A. Wheaton and Company, 1973).

2. D. C. Kocher, Radioactive Decay Data Tables, U.S. Department of Energy, Technical Information Center, DOE/TIC-11026 (1981). 
3. U. S. Department of Energy, DOE Order 5400.5, Radiation Protection of the Public and the Environment $(2-8-90)$.

4. D. I. Horrocks and M. H. Studier, Determination of Radioactive Noble Gases with a Liguid Scintillator, Analytical Chemistry, $1964,36,2077$.

5. F. Cejnar, L. Wilhelová, and P. Vrzala, Noble Gas solubility Measurement in Liquid Scintillator Solvents, Int. J. Applied Radiation and Isotopes, 1977, 28, 281.

6. R. N. Maddox, Gas Absorption, Section 14 in Chemical Engineers' Handbook, Fifth Edition (R. H. Perry and C. H. Chilton, Eds.) (New York: McGraw-Hill, 1973). 